\title{
Normobaric hypoxia-induced brain damage in wistar rat
}

\author{
Ding-Yu Hu ${ }^{1,2}$, Qin $\mathrm{Li}^{1}$, Bo Li ${ }^{3}$, Rong-Ji Dai ${ }^{1}$, Li-Na Geng ${ }^{1}$, Yu-Lin Deng ${ }^{1 *}$ \\ ${ }^{1}$ School of Life Science and Technology, Beijing Institute of Technology, Beijing, China; \\ ${ }^{2}$ Department of Fire Engineering, The Chinese People's Armed Police Force Academy, Langfang, Hebei, China; \\ ${ }^{3}$ Beijing Vocational College of Electronic Science, Beijing, China. \\ Email: chem hdy@yahoo.com.cn
}

Received 2 July 2009; revised 20 August 2009; accepted 28 August 2009.

\begin{abstract}
The biochemical indicators of wistar rat under low oxygen concentration, such as brain water content, necrosis, lactic acid and $\mathrm{Na}^{+}-\mathrm{K}^{+}$-ATPase, was detected to evaluate normobaric hypoxia-induced brain damage and to investigate the mechanism of wistar rat brain injury. Histopathological changes in brain tissue induced by hypoxia were investigated via hematoxylin and eosin stain (HE). Hypoxia induced factor-1a

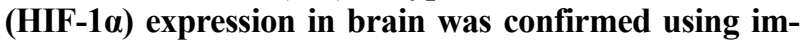
munohistochemistry. The results showed that the level of lactic acid was positively correlated with the degree of hypoxia, while concentration-dependent decrease in total $\mathrm{Na}^{+}-\mathrm{K}^{+}$-ATPase activity was observed. Compared with the control group, hypoxia group had a significant difference on brain water content under severe hypoxic conditions, the rate of brain necrosis increased obviously, followed by the increase of lactic acid level and the decrease of $\mathrm{Na}^{+}-\mathrm{K}^{+}$-ATPase activity. Histopathological analysis of brain confirmed that there was neuronal cell death in hippocampal gyrus. HIF-1 $\alpha$ expression enhanced the hypoxia adaptation capability of the rat model through regulating the expressions of multiple genes. Lactic acid, $\mathrm{Na}^{+}-\mathrm{K}^{+}$-ATPase and HIF$1 \alpha$ played an important role in brain injury as a possible mechanism.
\end{abstract}

Keywords: Hypoxia; Brain Damage; HIF-1 $\alpha$; Rat

\section{INTRODUCTION}

Hypoxia is an important pathobiological process in many diseases and causes changing of body functions easily $[1,2]$. Under airtight or demi-airtight environment, due to the effects of organism metabolic and impairment of gas exchange between the organization and environment, quality of the air in the cabin gets worse gradually, concentration of oxygen drops rapidly and concentration of carbon dioxide heightens rapidly. Hypoxia environment emerges quickly after appreciably long time. Hypoxia might lead to functional impairment, disturbance of consciousness, reaction dullness, retardation at action, damage of learning-memory function. Serious hypoxia might cause pathological damage or even death. Study on hypoxia mostly concentrated on hypoxic-ischemic encephalopathy (HIE) $[3,4]$, plateau hypoxia $[5,6]$, learning-memory [7]; therapy of various diseases induced by hypoxia and mechanisms [8,9], etc. Some studies had upgraded to cell and molecular level.

Hypoxia-induced brain damage is a hot research area of brain research. Brain damage may be induced by energy exhaustion in brain cell, overexpression of excitatory amino acids, oxygen free radical damage, apoptosis and inflammation, etc. The brain is susceptible to oxidative stress. This is due to the high content of polyunsaturated fatty acids, high rate of oxygen consumption, regional high concentrations of iron, and relatively low antioxidant capacity. These factors may predispose the premature infant, apoplexy patients to brain damage. Some of the mechanisms of hypoxia-induced brain damage were tried to be elucidated but not clearly completely nowadays. More experimental data would be needed. The investigation of the changes in energy metabolites and brain damage during hypoxia and brain hypoxic preconditioning might lead to the finding of an effective way to protect the brain from hypoxia injury.

The goal of this study was to investigate the biochemical effects of hypoxia on brain damage of rat model in the airtight cabin and provide more data for understanding the mechanism of brain damage. Brain water content, necrosis area, the levels of lactic acid and $\mathrm{Na}^{+}-\mathrm{K}^{+}$-ATPase activity were detected. HIF-1 $\alpha$ (hypoxia induced factor- $1 \alpha$ ) expression was confirmed using immunohistochemistry method. Histopathological changes of brain in rat model induced by hypoxia were investigated via hematoxylin and eosin stain (HE). All of rat models were exposed to hypoxia for $2 \mathrm{~h}$ at various concentrations of oxygen.

\section{MATERIALS AND METHODS}

\subsection{Animals}

Male wistar rats weighing 180-200g (provided by Institute of Laboratory Animal Science, Chinese Academy of Medical Science) were used in this study. Animals were 
allowed to acclimatize for at least 7 days prior to experiment. Animals were housed at a room temperature of $22 \pm 2^{\circ} \mathrm{C}$ and a relative humidity of $50 \pm 10 \%$ with controlled light (12-h light/12-h dark cycle, with the light switched on at 7 a.m.). Food and water were available ad libitum. All animals received humane care in compliance with the Guide for the Care and Use of Laboratory Animals published by Beijing Administration Office of Laboratory Animal.

\subsection{Normobaric Hypoxia Equipment}

Animals were placed in a custom-made 16-liter plastic normobaric hypoxia chamber. Fresh soda lime was put on the bottom of chamber. $\mathrm{O}_{2}$ and $\mathrm{N}_{2}$ cylinders were linked with the chamber. The concentration of $\mathrm{O}_{2}$ was controlled by infusing $\mathrm{N}_{2}$ at flow rate of $7.5 \mathrm{~L} / \mathrm{min}$. The concentrations of $\mathrm{O}_{2}$ and $\mathrm{CO}_{2}$ were monitored continuously respectively $[10] .18 \%, 15 \%, 12 \%, 10 \%, 8 \%, 6 \%$ $\mathrm{O}_{2}$ were designed and used in the experiment respectively. Compared to hypoxia group, control group, which exposed to normobaric normoxia $\left(21 \% \mathrm{O}_{2}\right)$ without food and water, was set up.

\subsection{Water Content of Brain Tissue}

After exposed to hypoxia for $2 \mathrm{~h}$, rats were anesthetized with $1 \%$ pentobarbital $(50 \mathrm{mg} / \mathrm{kg}$ of body weight, intraperitoneally) then killed by cervical dislocation. The brain of each rat was isolated and weighted. Water content of brain tissue detected by lyopyilization was calculated as a measure of hypoxia-induced brain damage, i.e. $\%$ water content $=100 \times(($ wet brain weight-dry brain weight) / wet brain weight) $\%$.

\subsection{Estimation of Brain Necrosis}

After exposed to hypoxia for $2 \mathrm{~h}$, rats were anesthetized with $1 \%$ pentobarbital $(50 \mathrm{mg} / \mathrm{kg}$ of body weight, intraperitoneally), then killed by cervical dislocation. The brain of each rat was isolated and coronally sectioned into five slices ( $2 \mathrm{~mm}$ thick), and then those slices were placed in 3\% 2, 3, 5-triphenyltetrazolium chloride (TTC) at $37{ }^{\circ} \mathrm{C}$ for $30 \mathrm{~min}$. Those slices were dried on filter paper and weighted respectively. Total damage sections (grey section) were isolated and weighted. The relative damage percentage was estimated by calculating the brain damage area percentage by total slice $(100 \times$ total damage section / total slice).

\subsection{Analysis of Lactic Acid and $\mathrm{Na}^{+}-\mathrm{K}^{+}$-ATPase}

The levels of lactic acid and $\mathrm{Na}^{+}-\mathrm{K}^{+}$-ATPase activity in rat model tissue were measured with kits (manufactured by Nanjing Jiancheng Bio-engineering Institute) according to the manufacturer's instruction. After exposed to hypoxia for $2 \mathrm{~h}$, rats were anesthetized with $1 \%$ pentobarbital $(50 \mathrm{mg} / \mathrm{kg}$ of body weight, intraperitoneally), killed by cervical dislocation. The brain tissue was iso- lated for biochemical examinations over an ice cube. After weighting, the isolated tissue were collected in 0.1 $\mathrm{M}$ phosphate buffer ( $\mathrm{pH}$ 7.4) and homogenized. The homogenates were centrifuged at $2000 \mathrm{r} \mathrm{min}^{-1}$ or $1000 \mathrm{r}$ $\min ^{-1}$ at $4^{\circ} \mathrm{C}$ for $10 \mathrm{~min}$. The supernatants were used for analysis of lactic acid and $\mathrm{Na}^{+}-\mathrm{K}^{+}$-ATPase activity respectively. The procedures of quantifying lactic acid and $\mathrm{Na}^{+}-\mathrm{K}^{+}$-ATPase activity were carried out according to the description of the kits. These indexes were evaluated by means of measurement of optical density at $530 \mathrm{~nm}$, $636 \mathrm{~nm}$ with a UV spectrophotometer respectively.

\subsection{Histopathological Examination}

In histopathological examination, rats were exposed to $6 \% \mathrm{O}_{2}$ for $2 \mathrm{~h}$ respectively and sacrificed by decapitation whose brains were taken out and transferred to $4 \%$ paraformaldehyde. Hippocampus sections were prepared (5 $\mu \mathrm{m}$ thick) and stained by hematoxylin and eosin. Stained sections were evaluated qualitatively (light microscopy) by an examiner blinded to experimental conditions.

\subsection{HIF-1 $\alpha$ Immunohistochemistry}

After exposed to $6 \% \mathrm{O}_{2}$ for $2 \mathrm{~h}$, the rats were anesthetized with $1 \%$ pentobarbital $(50 \mathrm{mg} / \mathrm{kg}$ of body weight, intraperitoneally ) and perfused through the ascending aorta with $200 \mathrm{ml}$ of $1 \% \mathrm{NaCl}$ solution, followed with $200 \mathrm{ml}$ of $4 \%$ paraformaldehyde. The brain of each rat was isolated and kept in the $4 \%$ paraformaldehyde solution until slicing. The brains were dehydrated in $10 \%$ sucrose for 1 day and then $30 \%$ sucrose solution for 2 days, till the brain sank to the bottom of the bottle. Hippocampus section were cut at $35 \mu \mathrm{m}$ thickness on a freezing microtome and processed for HIF-1 $\alpha$ immunohistochemistry. The sections were rinsed in PBS-T (add $1 \mathrm{ml}$ of tween 20 to $2 \mathrm{~L}$ of phosphate buffer saline), for three times. Then added with $3 \mathrm{ml}$ of $1 \% \mathrm{H}_{2} \mathrm{O}_{2}$ blocking solution at room temperature for $30 \mathrm{~min}$. After reaction, the slices were rinsed and then added with $2 \mathrm{ml}$ of 5\% BSA solution for $20 \mathrm{~min}$. Added 1:200 dilution of rabbit anti-HIF- $1 \alpha$ antibody, and weaved in the refrigerator for $24 \mathrm{~h}$. The reaction was followed by adding biotin labeled monoclone mice anti-rabbit antibody. The slices were rinsed, soaked in the SABC solution for $30 \mathrm{~min}$. Then DAB solution was used to stain for $10 \mathrm{~min}$. The sections were dehydrated in ascending alcohol concentrations, cleared and covered in xylene. Rabbit anti-HIF- $1 \alpha$ antibody, biotin labeled monoclone mice anti-rabbit antibody, $\mathrm{SABC}$ and $\mathrm{DAB}$ solution were purchased from Boster Biological Technology, LTD (Wuhan, Hubei, China).

\subsection{Statistical Analysis}

All results were expressed as mean \pm SEM. Statistical analysis of data was performed by applying one-way analysis of variance (ANOVA) followed by Tukey test. The $p$ values less than 0.05 were considered as statistically significant difference. 


\section{RESULTS}

\subsection{Water Content of Brain Tissue}

The increasing of water content of brain tissue was induced by hypoxia. While exposed to $8 \%, 6 \% \mathrm{O}_{2}$, water contents in the rat brain were the highest. The volumes of brain water content were $77.8 \%$ and $77.9 \%$ respectively. When exposed in $10 \% \mathrm{O}_{2}$ or more, the brain water contents were located near $76.8 \%$. Compared with $21 \% \mathrm{O}_{2}$ group, there was significant difference in the brain water content of $8 \%, 6 \% \mathrm{O}_{2}$ group (Figure 1, $\mathrm{p}<0.05)$.

\subsection{Brain Necrosis}

Reduction reaction of TTC started under the effect of chondriosome succinate dehydrogenase in competent cell and then red stabile and indiffusible substance would be formed, while reduction reaction of TTC did not start in infarction section and the color of the section would be grey. The method might be used to evaluate the necrosis of brain. Results showed that brain infarction ratio increased obviously under serious hypoxia condition $\left(6 \% \mathrm{O}_{2}\right)$. For the brain infarction ratio, there was a significant difference between group $21 \% \mathrm{O}_{2}$ and group $6 \% \mathrm{O}_{2}$ (Figure 2, $\mathrm{p}<0.05$ ).

\subsection{Lactic Acid}

When the rat was exposed to $10 \% \mathrm{O}_{2}$ or more, the level of lactic acid in $10 \%$ brain homogenate tissue changed from $1.23 \mathrm{mmol} \cdot \mathrm{L}^{-1}$ to $1.26 \mathrm{mmol} \cdot \mathrm{L}^{-1}$. while the rat model group $6 \% \mathrm{O}_{2}$ was exposed to $8 \% \mathrm{O}_{2}$ or less, the level of lactic acid increased significantly, it changed from $1.26 \mathrm{mmol} \cdot \mathrm{L}^{-1}$ to $4.2 \mathrm{mmol} \cdot \mathrm{L}^{-1}$ (Figure 3). The more serious the degree of hypoxia was, the higher the

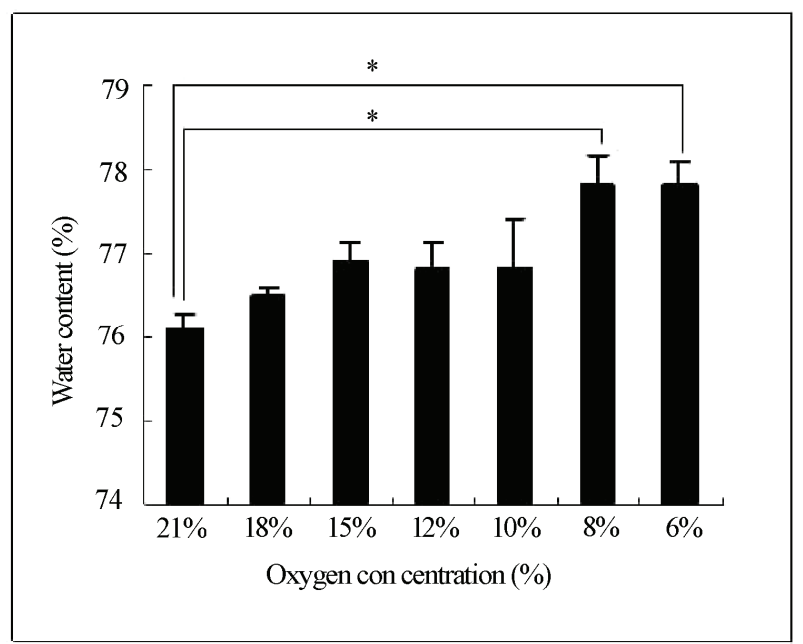

Figure 1. Brain water content at various concentrations of oxygen. $(* \mathrm{p}<0.05$ compared with the group $21 \%$ ). lactic acid level was. It increased obviously at $10 \% \mathrm{O}_{2}$ or less. Lactic acid was accumulated in the brain sharply at $6 \% \mathrm{O}_{2}$.

\section{4. $\mathrm{Na}^{+}-\mathrm{K}^{+}$-ATPase}

Hyperactivity of $\mathrm{Na}^{+}-\mathrm{K}^{+}$-ATPase was large enough to maintain the ion homeostasis in the range of $21 \% \sim 12 \%$ $\mathrm{O}_{2}$. The level of $\mathrm{Na}^{+}-\mathrm{K}^{+}$-ATPase activity decreased significantly at serious hypoxia $\left(\leq 8 \% \mathrm{O}_{2}\right)$ which induced the function disorder of cell due to cell oedema and atrophia (Figure 4).

\subsection{Histopathological Examination}

After exposed to $6 \% \mathrm{O}_{2}$ for $2 \mathrm{~h}$, the rat model was killed and the brain was taken out. Hippocampus sections were prepared for histopathological examination. Compared with the control group, histopathological analysis of brain confirmed that there was neuronal cell death in

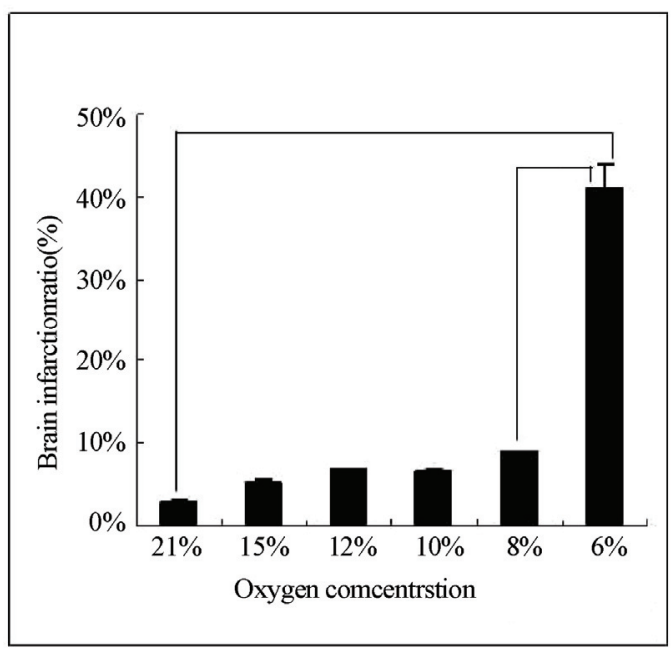

Figure 2. Brain necrosis at various concentrations of oxygen. (* $\mathrm{p}<0.05$ compared with the group $6 \%)$.

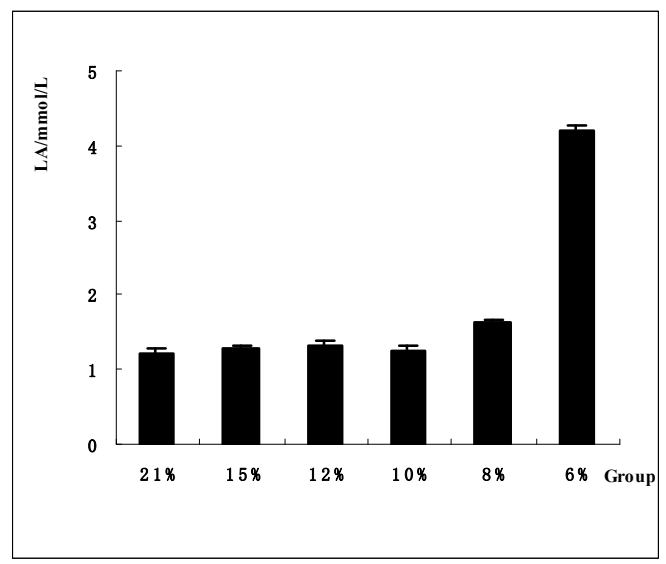

Figure 3. Lactic acid levels in rat models at various concentrations of oxygen. 


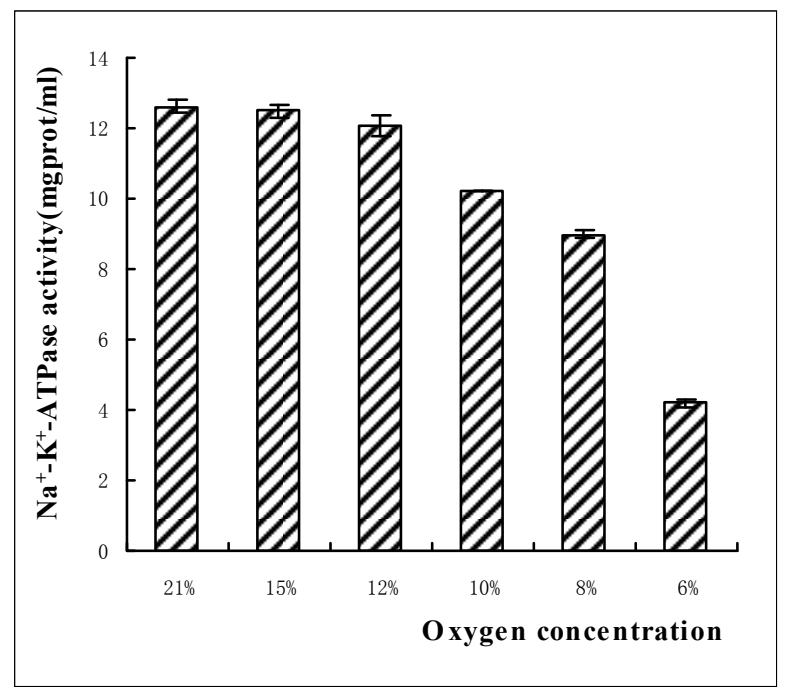

Figure 4. $\mathrm{Na}^{+}-\mathrm{K}^{+}$-ATPase activity in rat models at various concentrations of oxygen.

hippocampal gyrus of hypoxia group (Figure 5A). Previous study indicated that there were neuronal cells death in neuropile and cortex. When the concentration of oxygen was $8 \%, 10 \%$ separately, histopathological analysis of brain showed that there was no cell death in brain (Figure 5B and Figure 5C).

\subsection{HIF-1 $\alpha$ Immunohistochemistry}

Compared to the control group, expression of HIF-1 $\alpha$ in rat hippocampus section was obvious in Figure 6. Experiment confirmed that dilution ratio was an important factor to complete the HIF- $1 \alpha$ immunohistochemistry successfully because of the instability and low abundance of HIF- $1 \alpha$.

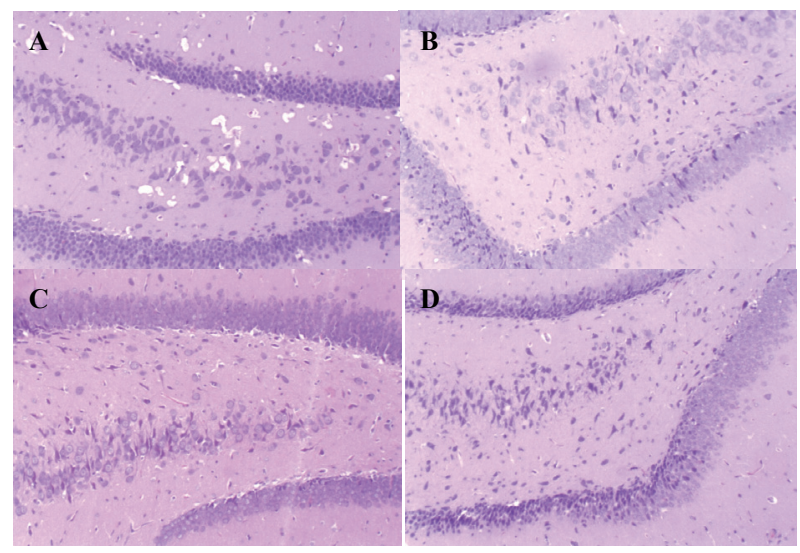

Figure 5. Representative photographs of histopathological examnation (HE) in the rat hippocampus under hypoxia conditions. (A: exposed to $6 \% \mathrm{O}_{2}$ for $2 \mathrm{~h}$; $\mathrm{B}$ : exposed to $8 \% \mathrm{O}_{2}$ for $2 \mathrm{~h}$; $\mathrm{C}$ : exposed to $10 \% \mathrm{O}_{2}$ for $2 \mathrm{~h}$; D: exposed to normobaric normoxia for $2 \mathrm{~h}$ without food and water).

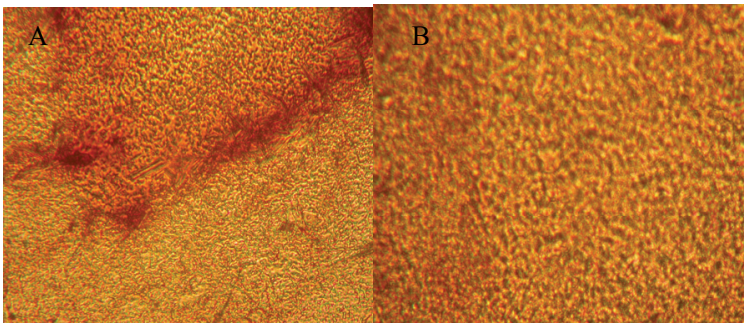

Figure 6. HIF-1 $\alpha$ immunohistochemistry photomicrographs of rat hippocampus section (dilution 1:200, A: exposed to $6 \% \mathrm{O}_{2}$ for $2 \mathrm{~h}$; $\mathrm{B}$ : exposed to normobaric normoxia for $2 \mathrm{~h}$ without food and water).

\section{DISCUSSION}

Extreme hypoxia would cause acidosis easily and lead to tissue oedema and cell death [11,12]. Results showed that the levels of lactic acid increased significantly under the severe hypoxia environment $\left(6 \% \sim 8 \% \mathrm{O}_{2}\right)$. It indicated that hypoxia led to anaerobic metabolism and metabolic acidosis. Pyruvic acid from glycolysis was converted by anaerobic metabolism to lactic acid mostly.

$\mathrm{Na}^{+}-\mathrm{K}^{+}$-ATPase would transport $\mathrm{Na}^{+}$ions and $\mathrm{K}^{+}$ions against their concentration gradient. The decrease of $\mathrm{Na}^{+}-\mathrm{K}^{+}$-ATPase activity showed that the loss of ion homeostasis occurred. It is generally believed that loss of ion homeostasis played an important role in the pathogenesis of brain cell damage. Extreme hypoxia-induced perturbation of ion homeostasis led to the intracellular accumulation of sodium and calcium ions, followed by subsequent activation of proteases and phospholipases and the formation of oxygen and nitrogen free radicals [13]. Consequently, the events would cause changing of functional and structural including cerebral edema, eventually lead to cell death. Under hypoxia condition, energy exhaustion would induce inhibition of $\mathrm{Na}^{+}$$\mathrm{K}^{+}$-ATPase activity and accumulation of lactic acid, followed by acidosis and cell apoptosis.

HIF-1 is a transcriptional activator that regulates the expression of multiple genes during continuous hypoxia [14]. HIF-1 is composed of a constitutively expressed HIF- $1 \beta$ and $\mathrm{O}_{2}$ regulated HIF- $1 \alpha$ subunit. Previous studies confirmed that HIF-1 played a general role in coordinating adaptive physiologic responses to hypoxia at the level transcription. HIF-1 $\alpha$ has also been implicated in the coordinate transcriptional activation of genes encoding glycolytic enzymes in hypoxia cells, which provide an alternative means of energy product under conditions of limited oxygen availability $[15,16]$. The results of immunohistochemistry confirmed that HIF- $1 \alpha$ was induced by hypoxia at $6 \% \mathrm{O}_{2}$. Expression of HIF- $1 \alpha$ enhanced the hypoxia adaptation capability of the rat model through regulating the expression of multiple genes. 


\section{CONCLUSIONS}

The values of lactic acid are positively correlated with the degree of hypoxia, while total $\mathrm{Na}^{+}-\mathrm{K}^{+}$-ATPase activity shows a concentration-dependent decrease. Compared with the control group; hypoxia group has a significant difference in brain water content under severe hypoxia condition. The area of brain necrosis increases sharply followed by the increase of lactic acid level and the decrease of $\mathrm{Na}^{+}-\mathrm{K}^{+}$-ATPase activity, neuronal cell death and HIF-1 expression appear in hippocampal gyrus obviously. Lactic acid, $\mathrm{Na}^{+}-\mathrm{K}^{+}$-ATPase and HIF-1 $\alpha$ played an important role as a possible mechanism in brain injury.

\section{ACKNOWLEDGEMENT}

This work was supported by Commission of Science Technology and Industry for National Defense (Grant No. A2220060042) and the National Natural Science Foundation of China (Grant No. 20705005).

\section{REFERENCES}

[1] I. L. Kanstrup, T. D.Poulsen and J. M. Hansen. (1999) Blood pressured and plasma catecholamine in acute and prolonged hypoxia effects of local hypothermia, Apple Phys, 87(6), 2053-8.

[2] Q. H. Chen. (2001) The changes of function and morphology of pulmonary arterial vessels in the pika at high altitude, Chin. J. Appl Phys, 17(2), 178-81.

[3] W. J. Xia. (2005) The effects of hematopoietic growth factors and tanshinone II A on neuro-protection, Doctor Dissertation, The Chinese University of Hong Kong, Hong kong, China.

[4] M. Christiane and H. Brahimi. (2007) Harnessing the hypoxia-inducible factor in cancer and ischemic disease, Biochem. Pharmacol, 73, 450-457.

[5] S. D. Aramjit and K. Manoj. (2007) cDNA cloning, gene organization and variant specific expression of HIF- $1 \alpha$ in high altitude yak (Bos grumiens), Gene, 386(1-2), 7380 .

[6] S. Fau, C. Po, B. Gillet, et al. (2007) Effect of the reperfusion after cerebral ischemia in neonatal rats using MRI monitoring, Experimental Neurology, 208(2), 297-304.

[7] L. Liu, T. van Groen, Inga Kadish, et al. (2009) DNA methylation impacts on learning and memory in aging, Neurobiology of Aging, 30(4), 549-560.

[8] G. D. Funk, A. G. Huxtable and A. R. Lorier. (2008) ATP in central respiratory control: A three-part signaling system, Respiratory Physiology \& Neurobiology, 164(1-2), 131-142.

[9] M. L. Peter. (2008) Opioidergic and dopaminergic modulation of respiration, Respiratory Physiology \& Neurobiology, 164(1-2), 160-167.

[10] J. E. Rice, R. C. Vannucci and J. B. Brierley. (1981) The influence of immaturity on hypoxia-ischemia brain damage in the rat, Ann. Neurol, 9, 131-141.

[11] W. M. Bernhardt, C. Warnecke, C. Willam, et al. (2007) Organ protection by hypoxia and hypoxia-inducible factors, Methods Enzymol, 435, 219, 221-245.

[12] O. Marta, S. Monika and A. Jan. (2008) Regulation of $\mathrm{pH}$ in the mammalian central nervous system under normal and pathological conditions: Facts and hypotheses, Neurochem Int, 52(6), 905-919.

[13] D. B. Kintner, Y. Wang and D. Sun. (2007) Role of membrane ion transport proteins in cerebral ischemic damage, Front. Biosci, 12, 762-770.

[14] G. L. Semenza. (2004) $\mathrm{O}_{2}$-regulated gene expression: Transcriptional control of cardiorespiratory physiology by HIF-1, J. Appl. Physiol, 96, 1173-1177.

[15] M. W. Charles, B. Greg and L. S. Gregg. (1996) In vivo expression of mRNAs encoding hypoxia-inducible factor 1, Biochem Biophys Res Commun, 225, 485-488.

[16] G. L. Semenza. (2001) HIF-1 and mechanisms of hypoxia sensing, Cell. Biology, 13, 167-171. 